\title{
Modelling biome shifts in the Indian subcontinent under scenarios of future climate change
}

\author{
Dina N. Rasquinha ${ }^{1, *}$ and Mahesh Sankaran ${ }^{1,2}$ \\ ${ }^{1}$ National Centre for Biological Sciences, Tata Institute of Fundamental Research, GKVK Campus, Bellary Road, Bengaluru 560 065, India \\ ${ }^{2}$ School of Biology, University of Leeds, Leeds LS2 9JT, UK
}

The Indian subcontinent is expected to witness significant changes in climatic conditions in the future, but the implications of such changes for future spatial distribution of different biomes in the subcontinent are unclear. We sought to understand the potential shifts in the distribution of biomes in India by 2070 under different emission scenarios, identify biomes and regions of the country that are particularly at risk from future changes in climate, and quantify uncertainties associated with the predictions. We used an ensemble classifier (random forest) to model current and potential future distribution of biomes in India for different climate trajectories under the newly developed representative concentration pathway (RCP) scenarios. Climate projections from 19 and 17 different general circulation models (GCMs) were used to predict future biome distributions in India under the RCP 4.5 and RCP 8.5 scenarios respectively. For each scenario, model outputs from different GCM projections were combined using a simple majority voting criterion. Approximately $630,000 \mathrm{sq} . \mathrm{km}(18 \%)$ of the country is predicted to experience biome shifts under the RCP 8.5 scenario and $486,000 \mathrm{sq} . \mathrm{km}(14 \%)$ under the RCP 4.5 scenario by 2070 . Drier tropical biomes are likely to be replaced by wetter biomes, while temperate biomes are predicted to be dominated by vegetation characteristic of a warmer climate in the future. There was a high to moderate level of agreement between predictions of different GCMs. Our results suggest that biome shifts will be largely concentrated in the east-central and northern parts of the country, with tropical and subtropical dry forests, savannas, grasslands and xeric habitats particularly at risk. Future studies should focus on elucidating the responses of different vegetation subformations within individual biomes in order to gain a finer-scale understanding of vegetation responses to future climate change in the Indian subcontinent.

Keywords: Bioclimatic envelope models, biome shifts, ensemble modelling, random forests, representative concentration pathways.

ANTHROPOGENIC activities are resulting in unprecedented changes in the Earth's climate system. Average global

*For correspondence. (e-mail: dina.rasquinha@gmail.com) temperatures have increased by about $0.85^{\circ} \mathrm{C}$ since 1880 , with the last three decades being successively warmer than any preceding decade since 1850 (ref. 1). Model predictions indicate that by the end of the 21 st century, global mean surface air temperatures are likely to increase from anywhere between $0.3^{\circ} \mathrm{C}$ and $4.8^{\circ} \mathrm{C}$, relative to the 1986-2005 average, depending on future emission scenarios ${ }^{1}$. Precipitation patterns have likewise changed across the globe with model predictions suggesting further changes by the end of the 21 st century, albeit in a spatially variable manner, with some regions witnessing increases and other decreases in mean annual precipitation, intra-annual variability and the frequency and intensity of extreme events ${ }^{1}$. Given the dominant control exerted by climate on the global distribution of species and biomes ${ }^{2-8}$, it is likely that such climatic changes will have dramatic effects on the distribution of species, and indeed entire biomes, in the future ${ }^{9-21}$.

Biome shifts in response to climate change in the 20th century have already been documented for several boreal, temperate and tropical ecosystems ${ }^{19}$. At the same time, several recent studies have also attempted to predict future shifts in the potential distribution of biomes under different scenarios of climate change ${ }^{19-29}$. Such projections of biome or vegetation shifts in response to climate change are typically based on one of two alternate approaches - bioclimatic envelope models (BEMs) or process-based dynamic global vegetation models DGVMs $^{13,19,22,27,29-34}$. BEMs assume that vegetationclimate relationships are static, and rely on correlations between climatic variables and current vegetation distributions to predict future distributions ${ }^{27,32,33}$. Processbased DGVMs on the other hand, simulate an array of ecological processes, including photosynthesis, plant carbon balance, phenology and fire to predict vegetation distribution $^{35,36}$. While DGVMs are more biologically realistic and are capable of capturing transient dynamics in response to changing climates, they are also computationally complex and require detailed information on physiology and life-history traits of species ${ }^{32,37}$. Such data are often lacking, particularly in the tropics, and in these cases BEMs, with their lower data requirements, can be a valuable tool to explore climate-vegetation relationships 
and serve as a first approximation for understanding climate impacts on vegetation distribution ${ }^{18,27,32,37,38}$.

In this study, we adopt a bioclimatic envelope modelling approach to predict the future distribution of potential vegetation types across the Indian subcontinent under different scenarios of climate change. Assessments of potential biome shifts in response to 21 st century climate change have been carried out for individual biomes ${ }^{26}$, as well as multiple biome types at global ${ }^{19,29,34}$ and regional scales $\left(\right.$ China $^{22}$, North America ${ }^{39}$, Catalonia ${ }^{15}$, North Spain $^{15,40}$, southwest Germany ${ }^{41}$, West Africa ${ }^{20}$, Central America $^{42}$, South America ${ }^{21}$ ) using both DGVMs and BEMs. For India, assessments of potential biome shifts in response to changing climates have been carried out at both countrywide ${ }^{43,44}$ and regional scales ${ }^{45}$. However, these earlier efforts have been either based on limited climate change scenarios $^{45}$, or under scenarios where increases in temperature and proportional increases in rainfall are the same across the entire subcontinent ${ }^{46}$, or have modelled the potential distribution of vegetation types based on outputs from a single regional climate Model (e.g. HadRM $3^{43,44}$ ), thus not accounting for variability among predictions of future climates between different climate models ${ }^{37,47,48}$. Consequently, we lack measures of uncertainty associated with these forecasts attributable to differences in climate modelling approaches.

In this study we aim to: (i) assess the potential distributions of biomes in India in 2070 under different climate change scenarios using a consensus approach based on an ensemble of several different GCMs, (ii) identify regions of the country that are potentially vulnerable to biome shifts in the future, and (iii) quantify measures of uncertainty associated with these predictions. Our projections were developed at a spatial resolution of 0.083 decimal degrees ( 100 sq. km) for two different climate change scenarios based on the newly developed representative concentration pathways (RCPs) of the Coupled Model Inter-comparison Project Phase 5 (CMIP5) - RCP 4.5 and 8.5. RCP 8.5 represents a business-as-usual scenario with no coordinated global effort on climate change mitigation, while RCP 4.5 represents a 'stabilizing' scenario where emissions stabilize shortly after 2100 (IPCC, 2013) $)^{1}$.

\section{Methods}

\section{Modelling current biome distribution}

We used the WWF-ecoregions map to delineate the current distribution of biomes in the Indian subcontinent ${ }^{49}$. The map recognizes 11 major biomes for the Indian region (Figure 1) based on the biogeographic classifications of Udvardy (1975), MacKinnon (1997), and Rodgers and Pawar $(1988)^{49}$. The WWF-ecoregions map has also been used for similar assessments to understand species and biome shifts due to climate change in other parts of the world ${ }^{47,50-54}$.

We used the high-resolution climate data derived from the WorldClim climate database (http://www.worldclim. org) to model the current distribution of biomes in India at a resolution of 5 arc-min (approx. $9 \mathrm{~km} \times 9 \mathrm{~km})^{55}$. The database provides 19 bioclimatic variables representing annual, seasonal and extreme environmental conditions for the time period 1950-2000. These data are widely used in similar examinations of climate-induced species and biome redistributions because of their global coverage and accessibility ${ }^{20,50,51,56-58}$, and also compare well with the archived monthly data of India Meteorological Department (IMD) ${ }^{46}$.

To account for multicollinearity amongst bioclimatic variables, we only selected predictor variables that were largely uncorrelated with others (Table S1, see Supplementary Material online) and were biologically meaningful $^{20,21}$. Our final set of explanatory variables included annual mean temperature, annual temperature range, mean annual precipitation, precipitation seasonality, precipitation of driest quarter, precipitation of warmest quarter, precipitation of the coldest quarter and elevation.

We modelled the current distribution of biomes (from Olson et $a l .{ }^{49}$ ) using an ensemble-based machine learning technique, the random forest (RF) algorithm ${ }^{59}$. We chose $\mathrm{RF}$ over other techniques since a preliminary analysis indicated that it outperformed other approaches, including multinomial logistic regression and general boosting models for modelling current biome distributions (results not provided here), as has also been shown in previous studies $^{33,60}$. In addition, the technique is also robust against over-fitting ${ }^{61}$. RF builds a number of decision trees based on a subset of the data (the training set), while the remaining data comprise the 'out-of-bag' sample and are used to estimate predictive error. Each tree is built using a random subsample (with replacement) of both the training dataset and predictor variables, and each tree 'votes' for the final class for each pixel. Finally, a class is assigned to each pixel based on a simple majority of votes for each class from all the trees grown ${ }^{59}$. All analyses were carried out using the 'random forest' package ${ }^{59}$ as implemented in $\mathrm{R}^{62}$.

We constructed our model using a subset of the available data for the Indian subcontinent, generated by sampling every fourth pixel using a systematic sampling scheme to account for spatial autocorrelation. Our final dataset included 10,424 pixels of which $75 \%$ was used as the training dataset to construct the RF model and the remaining $25 \%$ as the test dataset to assess predictive error. Our final model, which was used to predict biome distributions for the entire Indian subcontinent, was based on 800 classification trees with a subset of two randomly selected predictors chosen for splitting each node of the tree. 
(a)

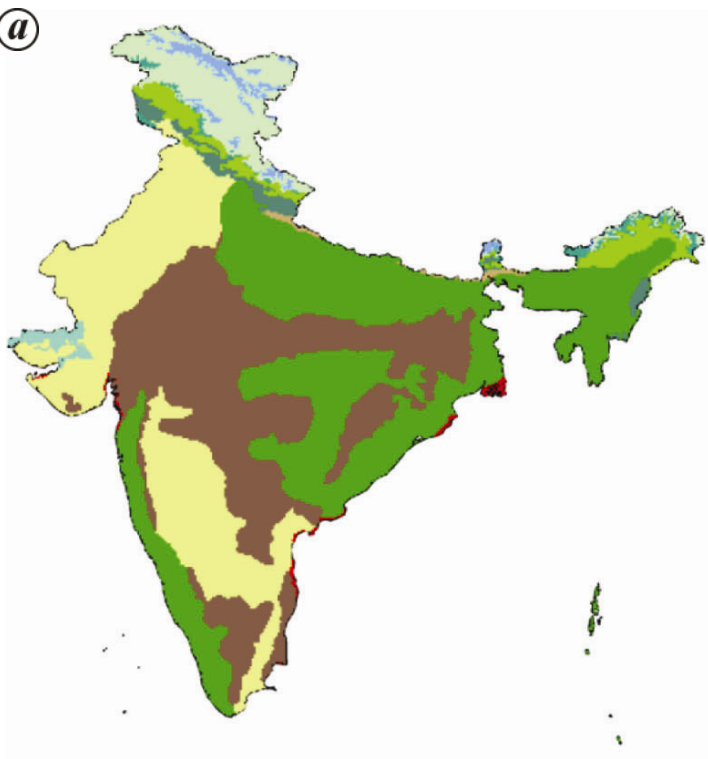

TROPICAL \& SUBTROPICAL MOIST BROADLEAF FORESTS TROPICAL \& SUBTROPICAL DRY BROADLEAF FORESTS TROPICAL \& SUBTROPICAL CONIFEROUS FORESTS TEMPERATE BROADLEAF \& MIXED FORESTS TEMPERATE CONIFEROUS FOREST TROPICAL \& SUBTROPICAL GRASSLANDS, SAVANNAS \& SHRUBLANDS (b)

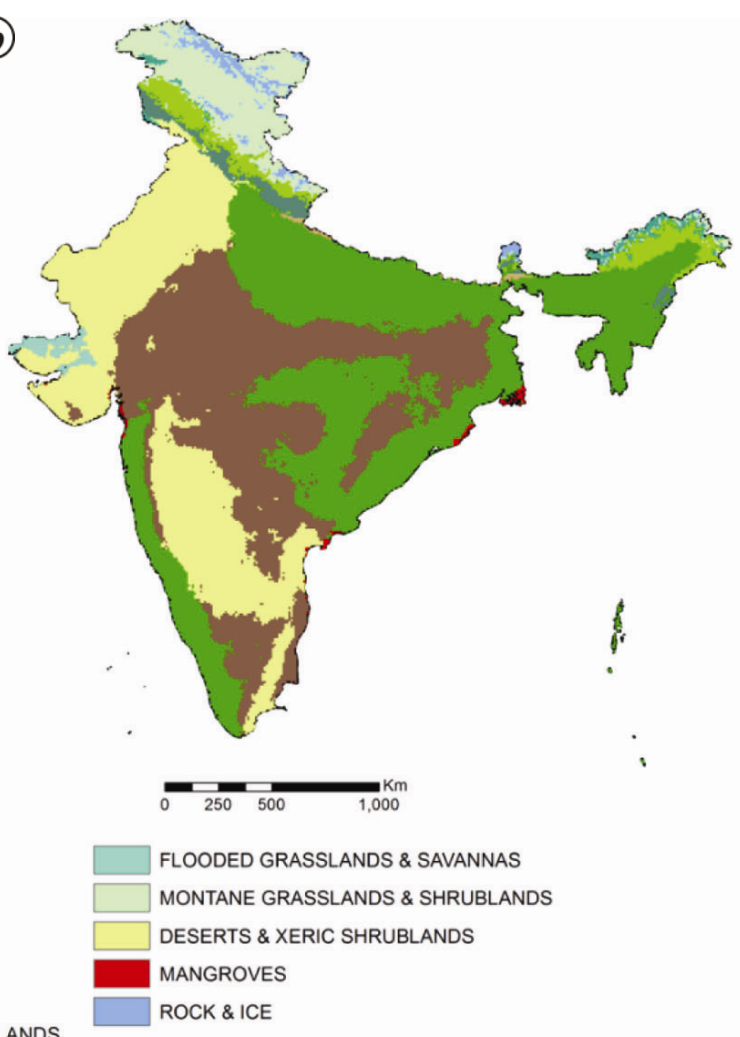

Figure 1. Distribution of different biomes in India (a) as delineated by Olson et $a l^{49}$ and $(\boldsymbol{b})$ as modelled by the random forest (RF) algorithm based on current climate.

\section{Model validation}

The accuracy of the RF model in predicting the current distribution of different biomes was evaluated for individual biomes as well as for the country as a whole. For individual biomes, we carried out a pixel-by-pixel comparison of the observed and predicted distribution of each biome to obtain the overall accuracy, commission and omission errors. The kappa $(\kappa)$ statistic was used to evaluate the predictive accuracy of the RF model for the country as a whole ${ }^{63}$.

\section{Future potential biome distribution, consensus in projections and uncertainty}

The RF model was then used to predict the future potential distribution of biomes in the Indian subcontinent for 2070 under two different emission scenarios - RCP 4.5 and 8.5. We used climate data from 19 different GCMs for the RCP 4.5 scenario, and from 17 GCMs for the RCP 8.5 scenario $^{55}$ (Table S2, see Supplementary Material online). A recent study has shown that CMIP5-based ensemble temperature and precipitation projections are able to capture the broad-scale climate patterns in India ${ }^{64}$. Further, the use of several GCMs allowed us to additionally assess uncertainties associated with the use of different models that generate future climate projections using different parameters and numerical methods.

The RF model was run separately for each GCM, and a final map of potential future biome distribution for each emission scenario (RCP 4.5 and 8.5) was generated by combining the outputs of all GCMs using a simple vote counting method, where each pixel was assigned the biome that was most frequently predicted by the different GCMs. We also generated a 'confidence map' for our projections to account for the variability amongst GCMs in their predictions of future climate by calculating, for each pixel, the percentage of GCMs that predicted the biome assigned to that pixel. We termed confidence in our projections as 'high' for pixels where the agreement between GCMs was more than $75 \%$, 'moderate' when it ranged between $50 \%$ and $75 \%$, and 'low' when it was less than $50 \%$. Similarly, we also generated an uncertainty map for the subcontinent by summing, for each pixel, the number of different biomes predicted by all the GCMs for each of the two emission scenarios.

Finally, to get an estimate of the extent to which areas predicted to undergo potential biome shifts in the future have already been transformed by humans, we summarized human population densities for these pixels using data from the Global Rural Urban Mapping Project ${ }^{65,66}$ (http://sedac.ciesin.columbia.edu/grumpv1), and also 
Table 1. Accuracy of the random forest model in predicting the current distribution of biomes for the Indian subcontinent. Error of omission refers to a class present at a particular pixel, but not predicted by the model, and error of commission refers to a class predicted to be present by the model, when in reality it is not. Producer's accuracy is calculated as the total number of pixels correctly predicted/total number of pixels known to exist for a particular class and consumer's accuracy is calculated as the total number of pixels correctly predicted/total number of pixels of that class predicted in the classified image

\begin{tabular}{|c|c|c|c|c|}
\hline Biome & $\begin{array}{l}\text { Omission } \\
\text { error }(\%)\end{array}$ & $\begin{array}{c}\text { Commission } \\
\text { error }(\%)\end{array}$ & $\begin{array}{c}\text { Producer's } \\
\text { accuracy }(\%)\end{array}$ & $\begin{array}{l}\text { Consumer's } \\
\text { accuracy }(\%)\end{array}$ \\
\hline Tropical and subtropical moist broadleaf forests & 4.1 & 4.8 & 96.0 & 95.2 \\
\hline Tropical and subtropical coniferous forests & 35.1 & 19.6 & 39.9 & 80.4 \\
\hline Temperate broadleaf and mixed forests & 19.9 & 18.4 & 83.5 & 81.6 \\
\hline Flooded grasslands and savannas & 11.1 & 10.6 & 90 & 89.4 \\
\hline Montane grasslands and shrublands & 8.8 & 10.6 & 91.9 & 89.4 \\
\hline Deserts and xeric shrublands & 3.5 & 4.5 & 96.6 & 95.5 \\
\hline Rock and Ice-covered areas & 43.4 & 19.1 & 69.8 & 80.9 \\
\hline
\end{tabular}

estimated the fraction of these pixels that currently lie within protected zones (national parks and wildlife sanctuaries) of the country.

\section{Results \\ Modelling current biome distributions}

We were able to model the current distribution of biomes with a high degree of accuracy (Figure 1). The classification error rates for individual biomes was typically low (see Table 1 and Table S3, Supplementary Material online for error matrix), and the overall predictive accuracy for the country as a whole was $93.41 \%$. The kappa coefficient of 0.91 indicated an almost perfect agreement between the modelled and observed biome distribution map. Misclassified pixels occurred most frequently around the boundaries of biomes.

\section{Biome shifts under climate change}

Although we modelled all biomes for the sake of completeness, we exclude the 'mangrove' biome from our interpretations here as its distribution is not necessarily climatically determined. Our model results indicate a consistent increase in the spatial extent of three biomes tropical and subtropical moist broadleaf forest, tropical and subtropical dry broadleaf forest, and montane grasslands and shrublands - by 2070 under both emission scenarios (Figure 2 and Table 2; projections for 2050 are additionally provided in Figure S1 and Table S4 the Supplementary Material online). The remaining biomes show a contraction in their range extents by 2070 (Figure 2 and Table 2; see Figure S1 and Table S4, Supplementary Material online for 2050 estimates).

Drier and currently more arid tropical regions appear particularly at risk, with most of the drier tropical biomes likely to be replaced by wetter biomes in the future. By 2070, tropical and subtropical moist broadleaf forests are likely to completely replace tropical and subtropical grasslands, savannas and shrublands, and also occupy about $51 \%$ of the area currently covered by tropical and subtropical coniferous forests, about $24 \%$ of the area of temperate broadleaf and mixed forests, about $18 \%$ of the area of tropical and subtropical dry broadleaf forests and about $5 \%$ of the deserts and xeric shrublands (see Table S5 Supplementary Material online for pairwise biome transitions for each scenario). Tropical and subtropical dry broadleaf forests will occupy about $23 \%$ of the area currently covered by deserts and xeric shrublands, and $5 \%$ of the area of tropical and subtropical moist broadleaf forests.

Further, about $16 \%$ of the area of deserts and xeric shrublands will be occupied by savannas and grasslands. Temperate regions, on the other hand, will likely be dominated by a warmer climate. Montane grasslands and shrublands will potentially occupy about $86 \%$ of the area currently covered by ice, $8 \%$ of the area of temperate coniferous forest and $3 \%$ of temperate broadleaf and mixed forests.

Overall, 486,243 sq. km (14\%) and 628,965 sq. km $(18 \%)$ of the Indian subcontinent are predicted to experience biome shifts by 2070 under the RCP 4.5 and 8.5 scenarios respectively (Figure 3). Most of the areas vulnerable to biome shifts are concentrated in the eastcentral, northern and western parts of India, largely at the ecotones between biomes (Figure 3). Of the pixels predicted to undergo biome shifts under the RCP 4.5 and 8.5 scenarios, $7.78 \%$ and $8.07 \%$ respectively, lie within protected areas. Of the total area of India that is currently protected, which includes national parks and wildlife sanctuaries, $\sim 18 \%$ and $24 \%$ will potentially experience biome shifts by 2070 under the RCP 4.5 and 8.5 scenarios respectively. Although some parts of eastern and northern India that are vulnerable to biome shifts have human 
Table 2. Predicted change in the spatial extent of different biomes by 2070, expressed as a percentage of the current area under the RCP 4.5 and RCP 8.5 scenarios. Estimates represent mean percentage change summarized across 19 GCMs for RCP 4.5 and 17 GCMs for RCP 8.5, for each biome

\begin{tabular}{lcc}
\hline Biome & RCP 4.5 & RCP 8.5 \\
\hline Tropical and subtropical grasslands, savannas and shrublands & $-73.62(-83.52,-63.73)$ & $-83.1(-91.63,-74.56)$ \\
Rock and ice-covered areas & $-71.79(-76.14,-67.44)$ & $-78.24(-81.48,-75)$ \\
Tropical and subtropical coniferous forests & $-33.1(-39.51,-26.7)$ & $-39.51(-47.95,-31.07)$ \\
Temperate broadleaf and mixed forests & $-15.7(-24.28,-7.12)$ & $-31.43(-43.86,-19)$ \\
Deserts and xeric shrublands & $-16.25(-23.13,-9.37)$ & $-28.78(-40.83,-16.73)$ \\
Flooded grasslands and savannas & $-14.61(-20.78,-8.45)$ & $-25.45(-33.7,-17.2)$ \\
Temperate coniferous forests & $-7.3(-12.13,-2.48)$ & $0.42(-8.25,9.1)$ \\
Tropical and subtropical dry broadleaf forests & $7.28(4,10.57)$ & $6(0.03,11.96)$ \\
Montane grasslands and shrublands & $11.26(10.26,12.27)$ & $11.35(10.39,12.32)$ \\
Tropical and subtropical moist broadleaf forests & $9.77(5.34,14.21)$ & $21.49(10.53,32.44)$ \\
\hline
\end{tabular}

Values in parentheses are the lower and upper limits of the $95 \%$ confidence interval.
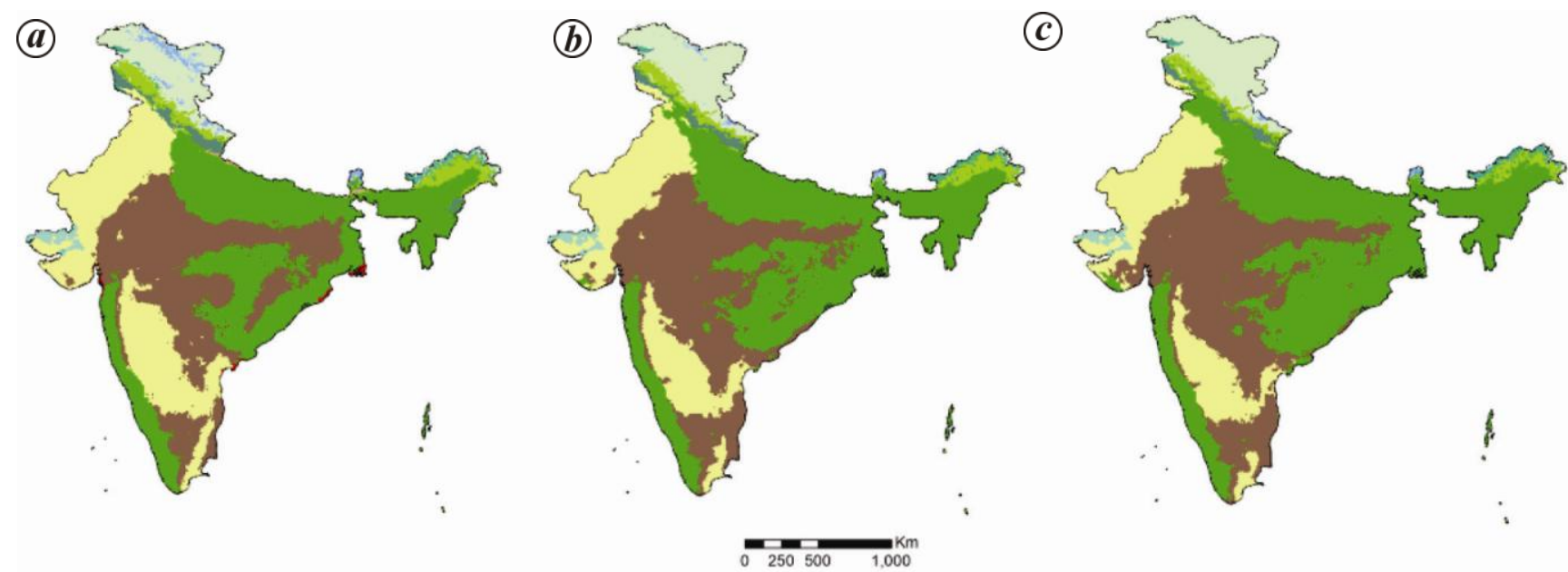

TROPICAL \& SUBTROPICAL MOIST BROADLEAF FORESTS
TROPICAL \& SUBTROPICAL DRY BROADLEAF FORESTS
TROPICAL \& SUBTROPICAL CONIFEROUS FORESTS
TEMPERATE BROADLEAF \& MIXED FORESTS
TEMPERATE CONIFEROUS FOREST
TROPICAL \& SUBTROPICAL GRASSLANDS, SAVANNAS \& SHRUBLANDS

Figure 2. Spatial distribution of different biomes in India as modelled by RF for ( $\boldsymbol{a}$ ) the present, $(\boldsymbol{b}) 2070$ under the RCP 4.5 scenario and ( $\boldsymbol{c}$ ) 2070 under the RCP 8.5 scenario.

densities as high as 1000 persons $\mathrm{km}^{-2}$, human population densities in other areas are much lower (Figure 3); nearly half of the area predicted to undergo biome shifts has density $<200 \mathrm{~km}^{-2}$, while $\sim 20 \%$ has density $<100 \mathrm{~km}^{-2}$ (Figure 3).

\section{Uncertainty of projections}

For most pixels, there is a high level of agreement in the predictions of future biome classes amongst the different GCMs for both emission scenarios (Figure 4). About 69\% $(81 \%)$ of the country shows high agreement amongst the different GCMS used for RCP 8.5 (4.5) scenario, while $29 \%(18 \%)$ and $2 \%(0.64 \%)$ of the country show moder- ate and low agreement respectively. This is also reflected in the number of different biomes predicted for each pixel by different GCMs (Figure 5). For any given pixel, the number of different predicted future biomes ranges from 1 to 5 , with different GCMs predicting at most 1 or 2 different potential biomes for large parts of the country (Figure 5).

\section{Discussion}

Our results indicate that in the absence of targeted climate change mitigation initiatives, over $628,000 \mathrm{sq} . \mathrm{km}$ of the Indian subcontinent will potentially undergo biome transitions by the latter part of the century. Arid and 
(a)

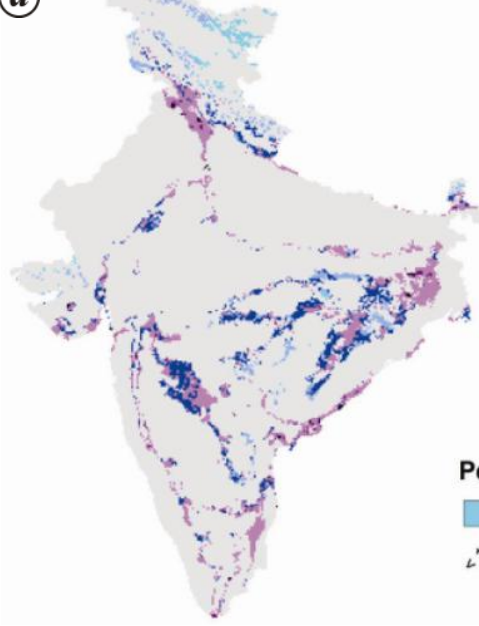

(b)

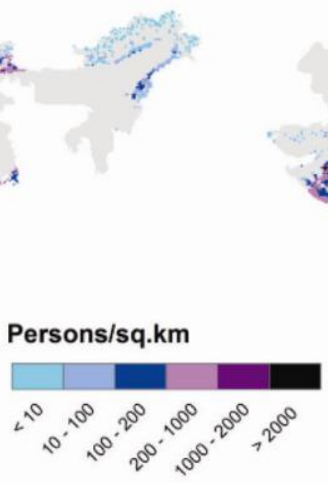

b)

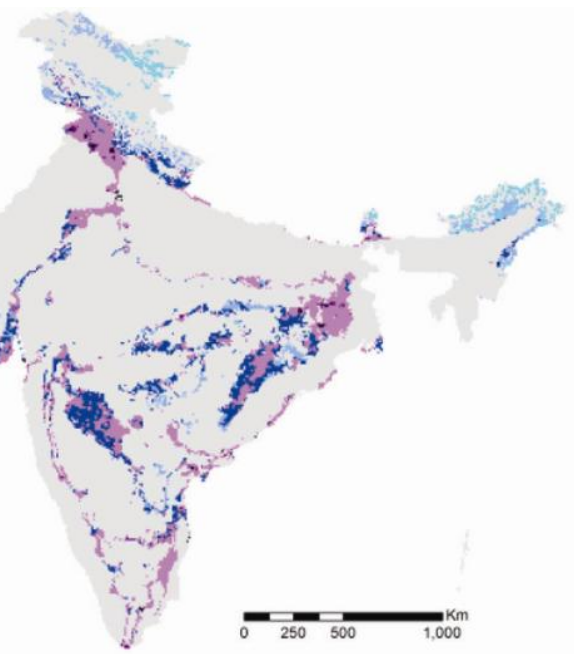

Figure 3. Regions of India predicted to undergo biome shifts (as shown by non-grey areas in the map) by 2070 under (a) RCP 4.5 scenario and (b) RCP 8.5 scenario. Approximately 14\% (486,243 sq. km) and 18\% (628,965 sq. km) of the country are predicted to witness potential biome shifts by 2070 under the RCP 4.5 and RCP 8.5 scenarios respectively. The legend describes the population density (persons/sq. $\mathrm{km}$ ) of areas predicted to undergo biome shifts for the two scenarios.
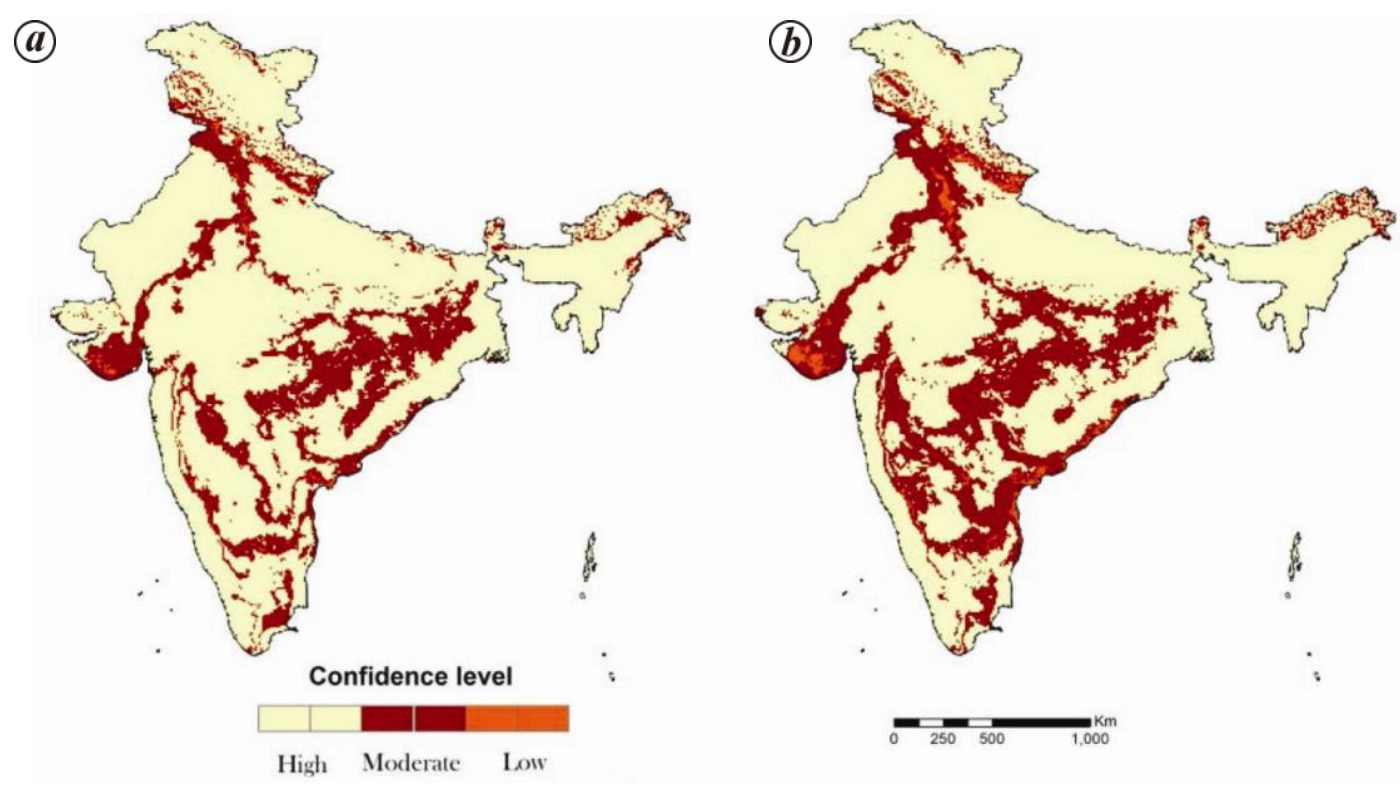

Figure 4. Level of agreement among the different general circulation models (GCMs) for (a) RCP 4.5 and (b) RCP 8.5 . Yellow areas on the map are those with high level of agreement amongst GCM predictions (>75\% of the GCMs predicted the same biome), red areas are those with moderate agreement $(>50 \%$, but $<75 \%)$ among GCMs, and orange areas are those with low agreement $(<50 \%)$ among the GCMs. For RCP 8.5, 69\% of the area shows high, 29\% moderate and $2 \%$ low agreement, while for RCP $4.5,81 \%$ shows high, $18 \%$ moderate and $0.6 \%$ low agreement.

semi-arid vegetation in tropical and subtropical parts of the country are likely to be replaced by moist broadleaved forests, while in temperate and high-elevation regions, montane grasslands and shrublands are predicted to expand at the expense of temperate broadleaved and mixed forests. These results are consistent with climate predictions from global and regional models, which suggest increases in precipitation and temperature over large parts of the country in the future ${ }^{67,68}$.

Using just temperature, precipitation and elevation, our RF model was able to capture the current distribution of biomes in India with a high degree of accuracy (>90\%), although there were differences between individual biomes, with some modelled more accurately than others (Table 1). Climatic variables associated with rainfall and temperature thus appear to be important regulators of coarse-scale biome distributions in India, such that directional changes in these drivers are likely to lead to biome shifts in the future. The biome-level classifications employed in this study are, however, fairly coarse-grained, with each biome, in turn, comprising multiple eco-regions characterized by distinct vegetation associations. Olson 

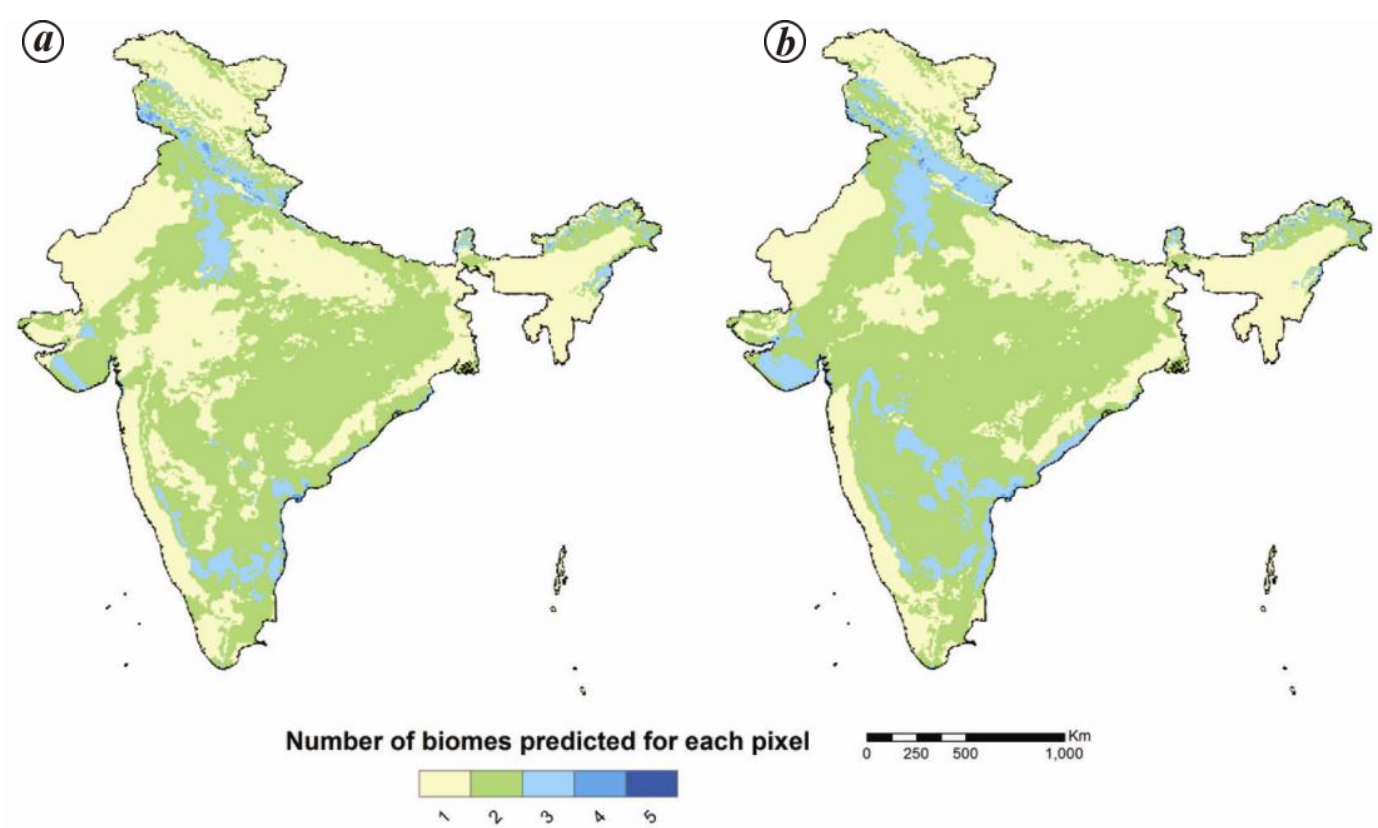

Figure 5. Number of biomes predicted for each pixel by the different GCMs for (a) RCP 4.5 and (b) RCP 8.5 scenarios. More the number of biomes, less reliable are the predictions and vice versa.

et al. $^{49}$ in fact recognized a total of 52 distinct ecoregions within India. At the level of these finer-scale ecoregions, the total area of the country that will potentially witness drastic vegetation shifts in the future is likely to be much higher than what our coarse biome-level estimates suggest.

Our results indicate that the spatial extent of the climate space that characterizes the 'tropical and subtropical moist broadleaf forest biome' in India, which includes both wet evergreen and moist deciduous forests, is likely to increase in the future. Overall, the spatial extent of this biome is predicted to increase by $\sim 20 \%$ by 2070 , with range increases largely occurring at the drier limits of the biome range, where moist broadleaf forests transition into 'tropical and subtropical dry broadleaf forests'. These results are in agreement with Zelazowski et al. ${ }^{26}$ who also reported on the potential for humid forest expansion into seasonal forest areas in mainland Southeast Asia and eastern India. Wet evergreen forests, which are currently restricted to the Western Ghats and North East India, both biodiversity hotspots, appear to be relatively stable and less at risk of undergoing large-scale biome shifts. Our results are additionally supported by other studies of future potential vegetation in the Indian subcontinent ${ }^{43,44}$, and are also in accordance with outputs from regional climate models which predict the greatest future increases in rainfall over the west coast and NE India ${ }^{67}$.

The spatial extent of tropical and subtropical dry broadleaf forests is likewise predicted to increase, albeit to a lesser extent $(\sim 5 \%)$, with increases once again occurring at the drier end of the biome range at the expense of more arid vegetation types. Overall, within the tropical and subtropical regions of India, range loss is expected to be the greatest for these drier vegetation types, including grasslands, savannas and other mixed tree-grass formations, and xeric habitats. Our results suggest that 'tropical and subtropical grasslands, savannas and shrublands' are especially vulnerable to biome shifts, potentially reducing in future by over $80 \%$. However, this may be an overestimate given that we were not able to model this biome with a particularly high degree of accuracy (Table 1). The 'tropical and subtropical grasslands, savannas and shrublands' biome, as classified by Olson et al. ${ }^{49}$, currently only comprises the tall grass systems of the Gangetic plain at the Himalayan foothills. However, other savanna and mixed tree-grass formations (ecoregions) also occur within the more arid biomes in the country ${ }^{69,70}$. These systems harbour unique biodiversity and support critical populations of several open habitat species $^{71-73}$, but are also amongst the most threatened habitats as a result of land-use change and tree-planting activities ${ }^{74,75}$. Our results suggest that these habitats are likely to be even more at risk in the future, with ongoing anthropogenic threats compounded by the potential for climate-driven biome shifts.

Amongst the temperate biomes of the country, the 'temperate broadleaf and mixed forests' of the Himalaya appear particularly at risk, losing as much as a third of their potential area. The vulnerability of these Himalayan temperate forests has also been highlighted by Chaturvedi et $a l .{ }^{44}$ based on their analysis of future potential vegetation of India using the IBIS DGVM, and is consistent with future temperature increases being particularly pronounced in northern India ${ }^{44,67}$. In contrast, our results 
suggest little to no change in the total spatial extent of 'temperate coniferous forests', but an expansion in the area covered by high-elevation 'montane grasslands and shrublands'. Overall, there was also an increase in the mean elevation occupied by these biomes in the future (2070) relative to current conditions (data not shown), with montane grasslands and shrublands expanding to higher elevation areas currently covered by snow and ice. Although we currently lack long-term empirical data to confirm whether high-elevation grasslands in the Himalaya are in fact moving upwards to colonize previously non-vegetated areas, these results are consistent with reports of climate-induced elevational range shifts for several species in the Himalaya ${ }^{76}$.

There was a high level of agreement in the predictions of different climate models for large parts of the country, although we did detect some uncertainty associated with different models, particularly for areas predicted to undergo biome shifts. In most of these cases, predictions from a subset of climate models indicated a potential biome shift whereas other models predicted no biome-shifts (i.e. number of predicted future biomes for the pixel was 2). However, for some pixels, the number of potential future biomes predicted by different models was as high as 5, reflecting the variability in future climate predictions of different GCMs. From a management perspective, recognition of uncertainties associated with potential future climates is important in order to more effectively integrate such uncertainty into management planning.

In contrast to more detailed process-based approaches, bioclimatic envelope models do not take into account the effects of several well-known drivers, including increasing $\mathrm{CO}_{2}$ concentrations and resultant plant responses and feedbacks, and the role of disturbances such as fire in maintaining or altering biome boundaries ${ }^{32,77}$. Furthermore, they also do not account for intra-seasonal changes in rainfall and temperature patterns, or the effects of extreme rainfall events which have been reported to be increasing in frequency across large parts of the Indian subcontinent ${ }^{78}$. Future work that couples process-based DGVM models with high-temporal resolution regional climate models for India (e.g. CORDEX) will undoubtedly provide us with a more nuanced understanding of potential future biome shifts. Nevertheless, we believe that our approach has provided valuable insights that serve as a first approximation for understanding and predicting potential biome shifts across the Indian subcontinent in the future. It is also important to recognize that even in the absence of a complete biome shift, climate change can induce species compositional changes within biomes with important implications for their functioning ${ }^{19}$. Thus, in addition to ensemble-based modelling efforts that use process-based DGVMs to predict biome and vegetation shifts at finer scales, there is also a need for long-term ground-based monitoring efforts in different biomes if we are to better understand climate change impacts on future vegetation dynamics in the Indian subcontinent.

1. Stocker, T. F. et al. (eds), Summary for policymakers. In Climate Change 2013: The Physical Science Basis. Contribution of Working Group I to the Fifth Assessment Report of the Intergovernmental Panel on Climate Change, Cambridge University Press, Cambridge, United Kingdom, 2013.

2. Von Humboldt, A. and Bonpland, A., Essay on the Geography of Plants, University of Chicago Press, Chicago, USA, 2010.

3. Köppen, W. and Geiger, R., Das geographische System der Klimate. In Handbuch der Klimatologie (ed.), Gebrüder Borntraeger, Berlin, 1936, pp. 1-46.

4. Holdridge, L. R., Determination of world plant formations from simple climatic data. Science, 1947, 105, 367-368.

5. Küchler, A. W., Vegetation Mapping, The Ronald Press Company, New York, 1967.

6. Whittaker, R. H., Communities and Ecosystems, Macmillan, New York, 1975.

7. Box, E. O., Predicting physiognomic vegetation types with climate variables. Plant Ecol., 1981, 45, 127-139.

8. Budyko, M. I., The Evolution of the Biosphere, D. Reidel Publishing Company, Dordrecht, 1986.

9. Emanuel, W. R., Shugart, H. H. and Stevenson, M. P., Climatic change and the broad-scale distribution of terrestrial ecosystem complexes. Climate Change, 1985, 7, 29-43.

10. Solomon, A. M., Transient response of forests to $\mathrm{CO}_{2}$-induced climate change: simulation modeling experiments in eastern North America, Oecologia, 1986, 68, 567-579.

11. Prentice, K. C., Bioclimatic distribution of vegetation for general circulation model studies. J. Geophys. Res., 1990, 95, 1181111830 .

12. Shugart, H. H., Using ecosystem models to assess potential consequences of global climatic change. Trends Ecol. Evol., 1990, 5, 303-307.

13. Neilson, R. P., Vegetation distribution: a possible biosphere source of $\mathrm{CO}_{2}$ during climate change. Water Air Soil Pollut., 1993, 70, 659-673.

14. Parmesan, C. and Yohe, G., A globally coherent fingerprint of climate change impacts across natural systems. Nature, 2003, 421, 37-42.

15. Peñuelas, J., Ogaya, R., Boada, M. and Jump, S. A., Migration, invasion and decline: changes in recruitment and forest structure in a warming-linked shift of European beech forest in Catalonia (NE Spain). Ecography, 2007, 30, 829-837.

16. Simpson, J. J., Stuart, M. C., Daly, C. and Biomes, H., A discriminant analysis model of Alaskan biomes based on spatial climatic and environmental data. Arctic, 2007, 60, 341-369.

17. Kelly, A. E. and Goulden, M. L., Rapid shifts in plant distribution with recent climate change. Proc. Natl. Acad. Sci. USA, 2008, 105, 11823-11826.

18. Lawler, J. J., Shafer, S. L., White, D., Kareiva, P., Maurer, E. P., Blaustein, A. R. and Bartlein, P. J., Projected climate-induced faunal change in the Western Hemisphere. Ecology, 2009, 90, 588-597.

19. Gonzalez, P., Neilson, R. P., Lenihan, J. M. and Drapek, R. J., Global patterns in the vulnerability of ecosystems to vegetation shifts due to climate change. Global Ecol. Biogeogr., 2010, 19, 755-768.

20. Heubes, J., Kühn, I., König, K., Wittig, R., Zizka, G. and Hahn, K., Modelling biome shifts and tree cover change for 2050 in West Africa. J. Biogeogr., 2011, 38, 2248-2258.

21. Tovar, C., Arnillas, C. A., Cuesta, F. and Buytaert, W., Diverging responses of tropical Andean biomes under future climate conditions. PLOS ONE, 8, e63634. 
22. Chen, X., Zhang, X. S. and Li, B. L., The possible response of life zones in China under global climate change. Global Planet. Change, 2003, 38, 327-337.

23. Salazar, L. F., Nobre, C. A. and Oyama, M. D., Climate change consequences on the biome distribution in tropical South America. Geophys. Res. Lett., 2007, 34, 1-6.

24. Schneider, R. R., Hamann, A., Farr, D., Wang, X. and Boutin, S., Potential effects of climate change on ecosystem distribution in Alberta. Can. J. For. Res., 2009, 39, 1001-1010.

25. Hirota, M., Nobre, C., Oyama, M. D. and Bustamante, M. M. C., The climatic sensitivity of the forest, savanna and forest-savanna transition in tropical South America. New Phytol., 2010, 187, 707719.

26. Zelazowski, P., Malhi, Y., Huntingford, C., Sitch, S. and Fisher, J. B., Changes in the potential distribution of humid tropical forests on a warmer planet. Phil. Trans. R. Soc. A, 2011, 369, 137-160.

27. Alo, C. A. and Wang, G., Potential future changes of the terrestrial ecosystem based on climate projections by eight general circulation models. J. Geophys. Res., 2008, 113, 1-16.

28. Warszawski, L. et al., A multi-model analysis of risk of ecosystem shifts under climate change. Environ. Res. Lett., 2013, 8, 1-10.

29. Reu, B., Zaehle, S., Bohn, K., Pavlick, R., Schmidtlein, S., Williams, J. W. and Kleidon, A., Future no-analogue vegetation produced by no-analogue combinations of temperature and insolation. Global Ecol. Biogeogr., 2014, 23, 156-167.

30. Leemans, R., Cramer, W. and Minnen, J. G. V. A. N., SCOPE 56 - Global change: effects on coniferous forests and grasslands. In Prediction of Global Biome Distribution using Bioclimatic Equilibrium Models, SCOPE 56, 1993, ch. 16, pp. 1-33.

31. Cramer, W. et al., Global response of terrestrial ecosystem structure and function to $\mathrm{CO}_{2}$ and climate change: results from six dynamic global vegetation models. Global Change Biol., 2001, 7, 357-373.

32. Pearson, R. G. and Dawson, T. P., Predicting the impacts of climate change on the distribution of species: are bioclimate envelope models useful? Global Ecol. Biogeogr., 2003, 12, 361371.

33. Lawler, J. J., White, D., Neilson, R. P. and Blaustein, A. R., Predicting climate-induced range shifts: model differences and model reliability. Global Change Biol., 2006, 12, 1568-1584.

34. Betts, R. A. et al., Climate and land use change impacts on global terrestrial ecosystems, fire, and river flows in the HadGEM2-ES earth system model using the representative concentration pathways. Biogeosci. Discuss., 2013, 10, 6171-6223.

35. Smith, B., The History, Development and Evaluation of Dynamic Global Vegetation Models, 2001, pp. 41-84.

36. Scheiter, S. and Higgins, S. I., Impacts of climate change on the vegetation of Africa: an adaptive dynamic vegetation modelling approach. Global Change Biol., 2009, 15, 2224-2246.

37. Garcia, R. A., Burgess, N. D., Cabeza, M., Rahbek, C. and Araújo, M. B., Exploring consensus in 21 st century projections of climatically suitable areas for African vertebrates. Global Change Biol., 2012, 18, 1253-1269.

38. Stephenson, N. L., Actual evapotranspiration and deficit:: biologically meaningful correlates of vegetation distribution across spatial scales. J. Biogeogr., 1998, 25, 855-870.

39. Laliberte, A. S. and Ripple, W. J., Range contractions of north American carnivores and ungulates. Bioscience, 2004, 54, 123.

40. Peñuelas, J., A global change-induced biome shift in the Montseny mountains (NE Spain). Global Change Biol., 2003, 9, 131-140.

41. Hanewinkel, M., Hummel, S. and Cullmann, D. A., Modelling and economic evaluation of forest biome shifts under climate change in Southwest Germany. For. Ecol. Manage., 2010, 259, 710-719.

42. Khatun, K., Imbach, P. and Zamora, J., An assessment of climate change impacts on the tropical forests of Central America using the Holdridge Life Zone (HLZ) land classification system. For. Biogeosci. For., 2013, 6, 183-189.

43. Ravindranath, N. H., Joshi, N. V., Sukumar, R. and Saxena, A., 2006. Impact of Climate Change on Forests in India, 2013, 1-12.

44. Chaturvedi, R. K., Gopalakrishnan, R., Jayaraman, M., Bala, G., Joshi, N. V., Sukumar, R. and Ravindranath, N. H., Impact of climate change on Indian forests: a dynamic vegetation modeling approach. Mitig. Adapt. Strat. Global Change, 2010, 16, 119-142.

45. Joshi, P. K., Rawat, A., Narula, S. and Sinha, V., Assessing impact of climate change on forest cover type shifts in Western Himalayan eco-region. J. For. Res., 2012, 23, 75-80.

46. Chakraborty, A., Joshi, P. K., Ghosh, A. and Areendran, G., Assessing biome boundary shifts under climate change scenarios in India. Ecol. Indicators, 2013, 34, 536-547.

47. Beaumont, L. J., Pitman, A., Perkins, S., Zimmermann, N. E. and Yoccoz, N. G., Impacts of climate change on the world's most exceptional ecoregions. Proc. Natl. Acad. Sci. USA, 2010, 108, 2306-2311.

48. Fordham, D. A., Wigley, T. M. L., Watts, M. J. and Brook, B. W., Strengthening forecasts of climate change impacts with multimodel ensemble averaged projections using MAGICC/SCENGEN 5.3. Ecography, 2012, 35, 4-8.

49. Olson, D. M. et al., Terrestrial ecoregions of the world: a new map of life on earth. BioScience, 2001, 51, 933-938.

50. Loarie, S. R., Duffy, P. B., Hamilton, H., Asner, G. P., Field, C. B. and Ackerly, D. D., The velocity of climate change. Nature, 2009, 462, 1052-1055.

51. Donoghue, M. J. and Erika, J. E., Biome shifts and niche evolution in plants. Annu. Rev. Ecol., Evol, Syst., 2014, 45, 547-557.

52. Gallagher, R. V., Beaumont, L. J., Hughes, L. and Leishman, M. R., Evidence for climatic niche and biome shifts between native and novel ranges in plant species introduced to Australia. J. Ecol., 2010, 98, 790-799.

53. Watson, J. E. M., Iwamura, T. and Butt, N., Mapping vulnerability and conservation adaptation strategies under climate change. Nature Climate Change, 2013, 3(11), 989-994.

54. Williams, J. W., Jackson, S. T. and Kutzbach, J. E., Projected distributions of novel and disappearing climates by 2100 AD. Proc. Natl. Acad. Sci., 2007, 104(14), 5738-5742.

55. Hijmans, R. J., Cameron, S. E., Parra, J. L., Jones, P. G. and Jarvis, A., Very high resolution interpolated climate surfaces for global land areas. Int. J. Climatol., 2005, 25, 1965-1978.

56. Broennimann, O., Treier, U. A., Müller-Schärer, H., Thuiller, W., Peterson, A. T. and Guisan, A., Evidence of climatic niche shift during biological invasion. Ecol. Lett., 2007, 10, 701-709.

57. Buermann, W., Saatchi, S., Smith, T. B., Zutta, B. R., Chaves, J. A., Milá, B. and Graham, C. H., Predicting species distributions across the Amazonian and Andean regions using remote sensing data. J. Biogeogr., 2008, 35, 1160-1176.

58. Klausmeyer, K. R. and Shaw, M. R., Climate change, habitat loss, protected areas and the climate adaptation potential of species in Mediterranean ecosystems worldwide. PLOS ONE, 2009, 4, e6392.

59. Liaw, A. and Wiener, M., Classification and regression by random forest. RNews, 2002, 2, 18-22.

60. Cutler, D. R., Edwards Jr, K. H. B., Cutler, A., Hess, K. T., Gibson, J. and Lawler, J., Random forests for classification in ecology. Ecology, 2007, 88, 2783-2792.

61. Breiman, L., Random forests. Mach. Learn., 2001, 45, 5-32.

62. R Core Team, R: a language and environment for statistical computing, R Foundation for Statistical Computing, Vienna, Austria, 2013; http://www.R-project.org/.

63. Stehman, S. V., Estimating the kappa coefficient and its variance under stratified random sampling. Photogramm. Eng. Remote Sensing, 1996, 62(4), 401-407.

64. Chaturvedi, R. K., Joshi, J., Jayaraman, M., Bala, G. and Ravindranath, N. H., Multi-model climate change projections for India 
under representative concentration pathways. Curr. Sci., 2012, 103, 791-802.

65. Balk, D. L., Deichmann, U., Yetman, G., Pozzi, F., Hay, S. I. and Nelson, A., Determining global population distribution: methods, applications and data. Adv. Parasitol., 2006, 62, 119-156.

66. Centre for International Earth Science Information Network, Columbia University, International Food Policy Research Institute, The World Bank, and Centro Internacional de Agricultura Tropical. Global rural-urban mapping project, version 1 (GRUMPv1): population density grid. NASA Socioeconomic Data and Applications Center, NY, 2011; http://dx.doi.org/10.7927/H4R20Z93; accessed on 14 October 2015.

67. Kumar, K. R. et al., High-resolution climate change scenarios for India for the 21 century. Curr. Sci., 2006, 90, 334-345.

68. Kumar, K. K., Patwardhan, S. K., Kulkarni, A., Kamala, K., Koteswara, Rao K. and Jones, R., Simulated projections for summer monsoon climate over India by a high-resolution regional climate model (PRECIS). Curr. Sci., 2011, 101, 312-326.

69. Ratnam, J. et al., When is a 'forest' a savanna, and why does it matter? Global Ecol. Biogeogr., 2011, 20, 653-660.

70. Sankaran, M. and Ratnam, J., African and Asian savannas. In Encyclopedia of Biodiversity (ed. Levin, S.), 2013, 2nd edn, p. 355.

71. Bond, W. J. and Parr, C. L., Beyond the forest edge: ecology, diversity and conservation of the grassy biomes. Biol. Conserv., 2010, 143, 2395-2404.

72. Vanak, A. T., Conservation and sustainable use of the dry grassland ecosystem in Peninsular India: a quantitative framework for conservation landscape planning, 2013.

73. Parr, C. L., Lehmann, C. E. R., Bond, W. J., Hoffmann, W. A. and Andersen, A. N., Tropical grassy biomes: misunderstood, neglected, and under threat. Trends Ecol. Evol., 2014, 29, 205-213.
74. Veldman, J. W. et al., Where tree planting and forest expansion are bad for biodiversity and ecosystem services. BioScience, 2015, $\mathbf{X X}, 1-8$.

75. Veldman, J. W. et al., Toward an old-growth concept for grasslands, savannas, and woodlands. Front. Ecol. Environ., 2015, 13, 154-162.

76. Telwala, Y., Brook, B. W., Manish, K. and Pandit, M. K., Climate-induced elevational range shifts and increase in plant species richness in a Himalayan biodiversity epicentre. PLoS ONE, 2013, 8, e57103.

77. Heikkinen, R. K., Luoto, M., Araújo, M. B., Virkkala, R., Thuiller, W. and Martin, T., Methods and uncertainties in bioclimatic envelope modelling under climate change. Prog. Phys. Geograph., 2006, 6, 751-777.

78. Krishnaswamy, J., Vaidyanathan, S., Rajagopalan, B., Bonell, M., Sankaran, M., Bhalla, R. S. and Badiger, S., Non-stationary and non-linear influence of ENSO and Indian Ocean dipole on the variability of Indian monsoon rainfall and extreme rain events. Climate Dyn., 2015, 45, 175-184.

ACKNOWLEDGEMENTS. We thank the Department of Biotechnology, Government of India (Grant: BT/01/NE/PS/NCBS/09) and the National Centre for Biological Sciences (NCBS), Bengaluru for financial support. We also thank Varun Varma and Yadugiri V. T. for providing useful comments on the manuscript and for discussions that shaped the study, and NCBS for providing the necessary facilities.

Received 7 December 2015; revised accepted 20 February 2016 doi: $10.18520 / \mathrm{cs} / \mathrm{v} 111 / \mathrm{i} 1 / 147-156$ 